\title{
The Protective Role of Resveratrol on Diabetic Cardiomyopathy in Streptozocin Induced Diabetic Rats
}

\author{
๑ İsmail Polat Canbolat1, ๑ Türker Çavuşoğlu2,3, ๑ Gürkan Yiğittürk2, ๑ Utku Ateş4, ๑ Oytun Erbaş̧5
}

\begin{abstract}
${ }^{1}$ Demiroğlu Bilim University Faculty of Medicine, Department of Cardiology, İstanbul, Turkey
${ }^{2}$ Ege University Faculty of Medicine, Department of Histology and Embryology, İzmir, Turkey

${ }^{3}$ Ege University Application and Research Center of Cord Blood Cell, İzmir, Turkey

${ }^{4}$ Demiroğlu Bilim University Faculty of Medicine, Department of Histology and Embryology, İstanbul, Turkey

5Demiroğlu Bilim University Faculty of Medicine, Department of Physiology, İstanbul, Turkey
\end{abstract}

\begin{abstract}
Objectives: We aimed to investigate the effect of resveratrol on diabetic cardiomyopathy in streptozocininduced diabetic rats.

Materials and Methods: Rats were injected with streptozocin to establish diabetes model. After four weeks, heart tissues were collected for histopathological examination and immunoexpression of nitric oxide synthases-2 (NOS-2) and transforming growth factor- $\beta 1$ (TGF- $\beta 1$ ). Lipid peroxidation was evaluated.

Results: In diabetic rats, cardiac muscle cell thickness (hypertrophy), TGF- $\beta 1$ and NOS-2 expression were increased significantly when compared to control group. Administration of resveratrol in diabetic rats causes a
\end{abstract}

significant reduction both in cardiac muscle cell thickness, TGF- $\beta 1$ and NOS- 2 expression in these rats.

Blood glucose levels were significantly increased in diabetic rats expectedly, but there was no important difference between diabetic rats and resveratrol administrated diabetic rats in terms of blood glucose levels.

Conclusion: We showed protective effects of resveratrol on dilated cardiomyopathy on diabetic rats by reducing oxidative stress. As the prevalence of diabetes mellitus is increasing, resveratrol supplementation could help preventing diabetic cardiomyopathy.

Keywords: Resveratrol, diabetic cardiomyopathy, type 2 diabetes mellitus

Address for Correspondence: İsmail Polat Canbolat, Demiroğlu Bilim University Faculty of Medicine, Department of Cardiology, İstanbul, Turkey

Phone: +90 5334299988 e-mail: ismailpolat.canbolat@demiroglu.bilim.edu.tr ORCID ID: orcid.org/0000-0002-2374-9693

Received: 30.04.2019 Accepted: 22.05.2019

Cite this article as: Canbolat İP, Çavuşoğlu T, Yiğittürk G, Ateş U, Erbaş O. The Protective Role of Resveratrol on Diabetic Cardiomyopathy in Streptozocin Induced Diabetic Rats. EJCM 2019;7(2):84-88.

DOI: 10.32596/ejcm.galenos.2019.00023

Presented in: This article was presented as an oral presentation at the $13^{\text {th }}$ International Congress of Update in Cardiology and Cardiovascular Surgery Congress.

${ }^{\circ}$ Copyright 2019 by Heart and Health Foundation of Turkey (TÜSAV) / E Journal of Cardiovascular Medicine published by Galenos Publishing House. 


\section{Introduction}

Diabetic cardiomyopathy (DCM) is a clinical entity diagnosed when ventricular dysfunction occurs after excluding coronary atherosclerosis and hypertension ${ }^{(1)}$. The mechanism leading to DCM is not clear yet but myocardial hypertrophy and fibrosis have been shown to be the major pathogenesis of $\mathrm{DCM}^{(2)}$. Activation of reactive oxygen species (ROS) linked pathways play a major role in the pathogenesis of myocardial hypertrophy and fibrosis ${ }^{(2)}$.

Malondialdehyde (MDA) is a three-carbon low molecular weight aldehyde produced from free radical species of poly unsaturated fatty acids reflecting the degree of lipid peroxidation ${ }^{(3)}$. Transforming growth factor- $\beta 1$ (TGF- $\beta 1$ ) is a multifunctional cytokine regulating cell proliferation and extracellular matrix production which leads to fibrosis in tissues and organs when produced excessively ${ }^{(4)}$. Nitric oxide synthases-2 (NOS-2) is absent in healthy states, rather it's expressed under inflammatory conditions ${ }^{(5)}$.

Resveratrol is a polyphenol mainly found in grape skin and seeds ${ }^{(6)}$. Resveratrol has a wide range of protective effect on ageing, inflammation and glycation ${ }^{(7)}$. In this study, we evaluated the protective role of resveratrol on streptozocin-induced diabetic rats.

\section{Materials and Methods}

\section{Animals}

Male Sprague Dawley albino mature rats at eight weeks, weighing 200-220 g, were used in the experiments. The animals had access to food and water ad libitum. The animals were housed under a temperature-controlled environment $\left(22-24^{\circ} \mathrm{C}\right)$ with light/dark cycles of $12: 12$ hours. Experimental procedures were approved by the Committee for Animal Research of Celal Bayar University. All animal studies are strictly conformed to the animal experiment guidelines of the Committee for Human Care.

\section{Experimental protocol}

Diabetes was induced by intraperitoneal (i.p.) injection of streptozocin (STZ, Sigma-Aldrich, Inc.; Saint Louis,
MO, USA) $(60 \mathrm{mg} / \mathrm{kg}$ in $0.9 \% \mathrm{NaCl}$, adjusted to a $\mathrm{pH}$ 4.0 with $0.2 \mathrm{M}$ sodium citrate) for 14 rats. Remaining rats without streptozocin injection were selected as control group ( $n=6)$. Diabetes was verified as blood glucose levels of $250 \mathrm{mg} / \mathrm{dL}$ and higher after 24 hours by evaluating blood glucose levels with the use of glucose oxidase reagent strips (Boehringer-Mannheim, Indianapolis). Diabetic rats were randomly divided into two groups; diabetes group treated with $1 \mathrm{~mL} / \mathrm{kg}$ saline (Diabetes) $(\mathrm{n}=6)$, and diabetes group treated with $10 \mathrm{mg} / \mathrm{kg}$ /day resveratrol (Sigma Aldrich), (Diabetes + resveratrol $)(n=6)$ was administrated by i.p. for four weeks.

The animals were euthanized and blood samples were collected by cardiac puncture. Removal of the heart was performed for histopathological examination.

\section{Histopathological examination of heart tissue}

All animals were anesthetized by an i.p. of ketamin $\left(40 \mathrm{mg} / \mathrm{kg}\right.$, (40 mg/kg, Alfamine ${ }^{\circledR}$, Ege Vet, Alfasan International B.V., Holland)/xylazine (4 mg/ $\mathrm{kg}$, Alfazyne ${ }^{\circledR}$, Ege Vet, Alfasan International B.V., Holland) and formaldehyde was used for histological and immunohistochemical studies. Formalin-fixed hearts cut into $5 \mu \mathrm{m}$ sections were stained with hematoxylin and eosin (H\&E). All sections were photographed with Olympus C-5050 digital camera mounted on Olympus BX51 microscope.

Computerized image analysis system was used to assess morphological analysis. Heart muscle cell hypertrophy degree was examined by light microscopy. Thickness of muscle cells was calculated from the cross-sectional image. Muscle fiber was measured by image analysis software (Image- Pro Express 1.4.5, Media Cybernetics, Inc. USA). Average of 50 cardiac muscle cell from each animal was used for analysis.

\section{NOS-2, TGF- $\beta 1$ immunoexpression}

For immunohistochemistry, sections were incubated in primary antibodies (TGF- $\beta 1$, NOS-2 Bioss, Inc.; $1 / 100$ ) for $24 \mathrm{~h}$ at $4^{\circ} \mathrm{C}$. Histostain-Plus Bulk kit (Bioss, Inc) against rabbit $\operatorname{IgG}$ was used to detect 
antibody, and the final product was visualized by 3.3' diaminobenzidine (DAB). All sections were washed in PBS and photographed with an Olympus C-5050 digital camera mounted on Olympus BX51 microscope.

\section{Measurement of plasma TGF- $\beta$}

Plasma TGF- $\beta$ were measured using commercially available enzyme-linked immunosorbent assay (ELISA) kit (Biosciences). TGF- $\beta$ levels were expressed as $\mathrm{pg} / \mathrm{mL}$.

\section{Evaluation of lipid peroxidation}

Malondialdehyde (MDA) levels as thiobarbituric acid reactive substance (TBARS) was measured for the evaluation of lipid peroxidation. MDA levels were expressed as $\mathrm{nM}$ and tetraethoxypropane was used for calibration.

\section{Statistical Analysis}

Non-parametric (Mann-Whitney U) test was used to assess all quantitative data. Between-group differences were assessed by Student's t-test. All data are shown as mean values \pm standard error of the mean. P values of $<0.05$ were regarded as statistically significant. All analyses were performed using SPSS v.21.0 for Windows (SPSS, Inc., Chicago, Illinois, USA).

\section{Results}

In diabetic rats, cardiac muscle cell thickness (hypertrophy), TGF- $\beta 1$ and NOS-2 expression were increased significantly when compared to control group (Figure 1 and 2). Administration of resveratrol in diabetic

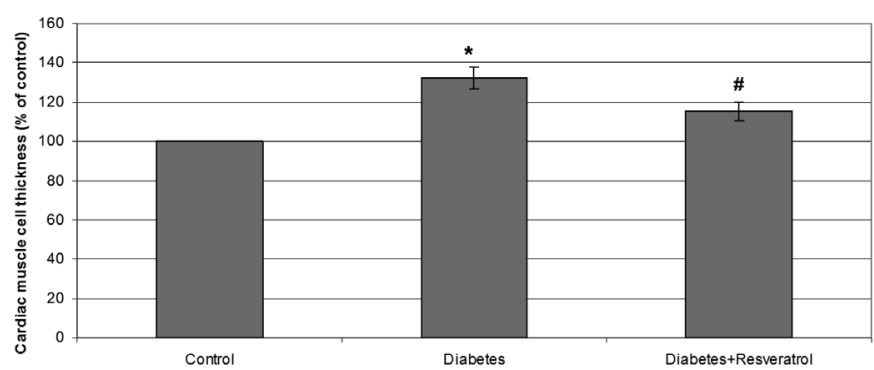

Figure 1. Cardiac muscle cell thickness in rats ${ }^{*} p<0.001$ Control group compared diabetes $\# p<0.05$ Diabetes group compared diabetes+resveratrol rats causes a significant reduction both in cardiac muscle cell thickness, TGF- $\beta 1$ and NOS- 2 expression in these rats (Table 1).

Diabetic rats had significantly higher levels of blood glucose levels but there was no significant difference between diabetic rats and resveratrol administrated diabetic rats in terms of blood glucose levels (Table 1). Plasma levels of TGF- $\beta 1$ and MDA were significantly elevated in diabetic rats and resveratrol administration caused significant reduction (Table 2).

\section{Discussion}

In this present study, resveratrol reduced oxidative stress and myocardial hypertrophy in streptozocin-induced diabetic rats. Diabetes mellitus is a condition defined by elevations on blood glucose levels leading to deaths mostly from cardiovascular causes ${ }^{(8)}$. Hyperglycemia and insulin resistance contributes to impaired mitochondrial calcium handling and oxidative stress leading to cardiac hypertrophy and fibrosis ${ }^{(9)}$.

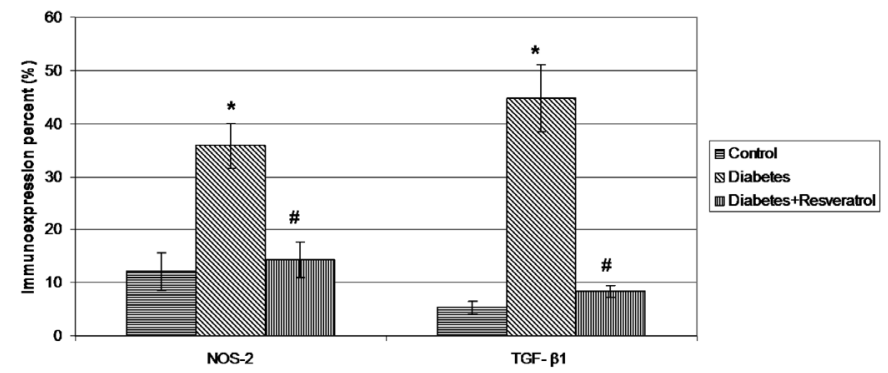

Figure 2. Immunoexpression percent of NOS-2 and TGF- $\beta 1$ ${ }^{*} p<0.05$ Control group compared diabetes $\# p<0.01$ Diabetes group compared diabetes+resveratrol

Table 1. Cardiac muscle cell thickness, TGF- $\beta 1$ and NOS-2 immunoexpression and blood glucose levels of rats

\begin{tabular}{|l|l|l|l|}
\hline & Control & Diabetes & $\begin{array}{l}\text { Diabetes and } \\
\text { resveratrol }\end{array}$ \\
\hline $\begin{array}{l}\text { Cardiac muscle cell } \\
\text { thickness (\% of control) }\end{array}$ & 100 & $132.3 \pm 5.6$ & $115.2 \pm 4.8$ \\
\hline $\begin{array}{l}\text { Immunoexpression NOS- } \\
\text { 2 percent (\%) }\end{array}$ & $12.1 \pm 3.5$ & $35.8 \pm 4.2$ & $14.3 \pm 3.4$ \\
\hline $\begin{array}{l}\text { Immunoexpression TGF- } \\
\text { B1 percent (\%) }\end{array}$ & $5.3 \pm 1.2$ & $44.7 \pm 6.3$ & $8.4 \pm 1.1$ \\
\hline \begin{tabular}{l} 
Blood glucose (mg/dL) \\
\hline NOS-2: Nitric oxide synthases -2, TGF- $\beta 1$ : Transforming growth factor-b1
\end{tabular} & $103.2 \pm 7.2$ & $482.3 \pm 30.4$ & $468.4 \pm 18.5$ \\
\hline
\end{tabular}


The role of resveratrol on blood glucose levels is conflicting. Lekli et al. showed that resveratrol reduces the blood glucose levels on diabetic rats ${ }^{(10)}$. However, some other studies suggested that resveratrol has no effect on blood glucose levels ${ }^{(11,12)}$. In our study, blood glucose levels were decreased, but this change was non-significant compared to diabetic rats who did not receive resveratrol treatment. These conflicting results in studies may suggest that the protective role of resveratrol on DCM is not related to improved hyperglycemia.

Cardiac fibrosis has a major role in the pathogenesis of DCM. TGF- $\beta 1$ is a regulator cytokine for cell proliferation and excessive production of TGF- $\beta 1$ leads to tissue fibrosis ${ }^{(13)}$. TGF- $\beta 1$ has been showed to be overexpressed in $\mathrm{DCM}^{(14,15)}$. Zhang et al. investigated the role of microRNA-155 on myocardial fibrosis induced by diabetes in mice and showed that myocardial fibrosis was regulated via TGF- $\beta 1$-Smad 2 signaling pathway ${ }^{(16)}$. Resveratrol had been shown to reduce pulmonary fibrosis in rats ${ }^{(17)}$. In our study, the level of TGF- $\beta 1$ was upregulated in diabetic rats as shown in previous studies, and administration of resveratrol reduced the level of TGF- $\beta 1$.

Oxidative stress is defined as an imbalance between generation of ROS and the antioxidant defense. Oxidative stress plays an important role in the process of diabetic complications ${ }^{(18)}$. Mitochondrial oxidative stress and ROS generation had been shown to be elevated in diabetic rats contributing to myocardial hypertrophy and fibrosis ${ }^{(19)}$.

Table 2. Plasma levels of TGF- $\beta 1$ and MDA

\begin{tabular}{|c|c|c|}
\hline & $\begin{array}{l}\text { TGF-Beta } \\
\text { (pg/mL) }\end{array}$ & MDA (nM) \\
\hline Normal Control (group 1) & $10.2 \pm 2.8$ & $94.2 \pm 11.4$ \\
\hline Diabetes (saline treatment) (group 2) & $43.5 \pm 5.1^{*}$ & $402.8 \pm 32.5^{\star}$ \\
\hline $\begin{array}{l}\text { Diabetic rat (resveratrol treatment) } \\
\text { (group 3) }\end{array}$ & $19.7 \pm 2.9^{\#}$ & $286.1 \pm 22.3^{\# \#}$ \\
\hline \multicolumn{3}{|c|}{$\begin{array}{l}\text { TGF- } \beta 1 \text { : Transforming growth factor- } b 1, M D A \text { : Malondialdehyde } \\
{ }^{*} p<0.000 \text {, saline tretment diabetic rats compared control group } \\
{ }^{\#} p<0.001 \text {, resveratrol treatment diabetic rats compared saline tretmen } \\
\text { diabetic rats } \\
\# \# p<0.0001, \text { resveratrol treatment diabetic rats compared saline tretmen } \\
\text { diabetic rats }\end{array}$} \\
\hline
\end{tabular}

Resveratrol is a well-confirmed antioxidant inhibiting excessive ROS production and lipid peroxidation ${ }^{(20)}$. MDA, final product of polyunsaturated fatty acid peroxidation, is indirectly reflecting the degree of cell damage. Fang et al. had shown increased expression of antioxidant enzymes and reduced MDA levels in diabetic mice treated with resveratrol ${ }^{(11)}$. In our study, the level of MDA was significantly increased as shown in previous studies, but administration of resveratrol reduced the level of MDA.

Nitric oxide synthases (NOS) mediates the synthesis of nitric oxide (NO), a short-living free radical that is an important mediator for cardiac contractility and vasodilatation $^{(21)}$. NOS-2 isoform, known as induced NOS, is expressed only under unhealthy conditions contributing to endothelial dysfunction ${ }^{(21)}$. NOS-2 level was found to be elevated in cardiomyocytes in myocarditis, dilated cardiomyopathy ${ }^{(22)}$. Mungrue et al. showed that cardiomyocyte overexpression of NOS-2 resulted in peroxynitrite generation, heart block and sudden death ${ }^{(5)}$. In our study, the level of NOS-2 was significantly increased. Administration of resveratrol reduced the level of NOS-2.

\section{Study Limitations}

As a limitation of our study, streptozocin induced diameters mellitus may cause atherosclerotic heart disease, we didn't perform coronary artery histopathological examination. We may have missed atherosclerosis.

\section{Conclusion}

In conclusion, we demonstrated protective effects of resveratrol on dilated cardiomyopathy on diabetic rats by reducing oxidative stress. As the prevalence of DM is increasing, resveratrol supplementation could help preventing diabetic cardiomyopathy.

\section{Ethics}

Ethics Committee Approval: Experimental procedures were approved by the Committee for Animal Research of Celal Bayar University. All animal studies are 
strictly conformed to the animal experiment guidelines of the Committee for Human Care.

Peer-review: Externally peer-reviewed.

\section{Authorship Contributions}

Surgical and Medical Practices: O.E., T.Ç., G.Y., Concept: İ.P.C., O.E., Design: İ.P.C., O.E., U.A., Data Collection or Processing: İ.P.C., O.E., Analysis or Interpretation: İ.P.C., O.E., Literature Search: İ.P.C., Writing: İ.P.C.

Conflict of Interest: No conflict of interest was declared by the authors.

Financial Disclosure: The authors declared that this study received no financial support.

\section{References}

1. Rydén L, Grant PJ, Anker SD, et al. ESC Guidelines on diabetes, prediabetes, and cardiovascular diseases developed in collaboration with the EASD: the Task Force on diabetes, pre-diabetes, and cardiovascular diseases of the European Society of Cardiology (ESC) and developed in collaboration with the European Association for the Study of Diabetes (EASD). Eur Heart J 2013;34:3035-87.

2. Clark RJ, McDonough PM, Swanson E, et al. Diabetes and the accompanying hyperglycemia impairs cardiomyocyte calcium cycling through increased nuclear O-GlcNAcylation. J Biol Chem 2003;278:44230-7.

3. Cordis GA, Das DK, Riedel W. High-performance liquid chromatographic peak identification of 2,4-dinitrophenylhydrazine derivatives of lipid peroxidation aldehydes by photodiode array detection. J Chromatogr A 1998;798:117-23.

4. Border WA, Noble NA. Transforming growth factor beta in tissue fibrosis. N Engl J Med 1994;331:1286-92.

5. Mungrue IN, Gros R, You X, et al. Cardiomyocyte overexpression of iNOS in mice results in peroxynitrite generation, heart block, and sudden death. $\mathrm{J}$ Clin Invest 2002;109:735-43.

6. Shrikanta A, Kumar A, Govindaswamy V. Resveratrol content and antioxidant properties of underutilized fruits. J Food Sci Technol 2015;52:383-90.

7. Galiniak S, Aebisher D, Bartusik-Aebisher D. Health benefits of resveratrol administration. Acta Biochim Pol 2019;66:13-21.
8. Cho NH, Shaw JE, Karuranga S, et al. IDF Diabetes Atlas: Global estimates of diabetes prevalence for 2017 and projections for 2045. Diabetes Res Clin Pract 2018;138:271-81.

9. Sung MM, Hamza SM, Dyck JR. Myocardial metabolism in diabetic cardiomyopathy: potential therapeutic targets. Antioxid Redox Signal 2015;22:1606-30.

10. Lekli I, Szabo G, Juhasz B, et al. Protective mechanisms of resveratrol against ischemia-reperfusion-induced damage in hearts obtained from Zucker obese rats: the role of GLUT-4 and endothelin. Am J Physiol Heart Circ Physiol 2008;294:H859-66.

11. Fang WJ, Wang CJ, He Y, Zhou YL, Peng XD, Liu SK. Resveratrol alleviates diabetic cardiomyopathy in rats by improving mitochondrial function through PGC-1 $\alpha$ deacetylation. Acta Pharmacol Sin 2018;39:5973

12. Schmatz R, Schetinger MR, Spanevello RM, et al. Effects of resveratrol on nucleotide degrading enzymes in streptozotocin-induced diabetic rats. Life Sci 2009;84:345-50.

13. Border WA, Ruoslahti E. Transforming growth factor-beta in disease: the dark side of tissue repair. J Clin Invest 1992;90:1-7.

14. Zhou T, Li HY, Zhong H, Zhong Z. Relationship between transforming growth factor- $\beta 1$ and type 2 diabetic nephropathy risk in Chinese population. BMC Med Genet 2018;19:201.

15. Guo Y, Gupte M, Umbarkar P, et al. Entanglement of GSK-3 $\beta$, $\beta$-catenin and TGF- $\beta 1$ signaling network to regulate myocardial fibrosis. J Mol Cell Cardiol 2017;110:109-20.

16. Zhang D, Cui Y, Li B, Luo X, Li B, Tang Y. miR-155 regulates high glucose-induced cardiac fibrosis via the TGF- $\beta$ signaling pathway. Mol Biosyst 2016;13:215-24.

17. Wang J, He F, Chen L, et al. Resveratrol inhibits pulmonary fibrosis by regulating miR-21 through MAPK/AP-1 pathways. Biomed Pharmacother 2018;105:37-44

18. Susztak K, Raff AC, Schiffer M, Böttinger EP. Glucose-induced reactive oxygen species cause apoptosis of podocytes and podocyte depletion at the onset of diabetic nephropathy. Diabetes 2006;55:225-33.

19. Sverdlov AL, Elezaby A, Qin F, et al. Mitochondrial Reactive Oxygen Species Mediate Cardiac Structural, Functional, and Mitochondrial Consequences of Diet-Induced Metabolic Heart Disease. J Am Heart Assoc 2016;5pii:e002555.

20. Liguori I, Russo G, Curcio F, et al. Oxidative stress, aging, and diseases. Clin Interv Aging 2018;13:757-72.

21. Lind M, Hayes A, Caprnda M, et al. Inducible nitric oxide synthase: Good or bad? Biomed Pharmacother 2017;93:370-5.

22. Salvemini D, Marino MH. Inducible nitric oxide synthase and inflammation. Expert Opin Investig Drugs 2005; 7:65-75. 